Please do not remove this page

RMIT

UNIVERSITY

\title{
Microfluidic dielectrophoretic cell manipulation towards stable cell contact assemblies
}

Ali, Mohd; Kayani, Aminuddin; Yeo, Leslie; Chrimes, Adam; Ahmad, Muhammad; Ostrikov, Kostya; Majlis, Burhanuddin

https://researchrepository.rmit.edu.au/esploro/outputs/9921863569901341/filesAndLinks?institution=61RMIT_INST\&index=null

Ali, M., Kayani, A., Yeo, L., Chrimes, A., Ahmad, M., Ostrikov, K., \& Majlis, B. (2018). Microfluidic dielectrophoretic cell manipulation towards stable cell contact assemblies. Biomedical Microdevices, 20(4), 1-13. https://doi.org/10.1007/s10544-018-0341-1

Document Version: Accepted Manuscript

Published Version: https://doi.org/10.1007/s10544-018-0341-1

Repository homepage: https://researchrepository.rmit.edu.au

(c) Springer Science+Business Media, LLC, part of Springer Nature 2018

Downloaded On 2023/04/26 21:09:52 +1000 


\title{
Microfluidic Dielectrophoretic Cell Manipulation Towards Stable Cell Contact Assemblies
}

\author{
Mohd Anuar Md Ali ${ }^{1}$ Aminuddin Bin Ahmad Kayani' ${ }^{2,3} \bullet$ Leslie Y. Yeo ${ }^{4}$ Adam F. Chrimes ${ }^{4} \bullet$ \\ Muhammad Zamharir Ahmad ${ }^{5}$ Kostya (Ken) Ostrikov Ko $^{6}$ - Burhanuddin Yeop Majlis ${ }^{1}$
}

Received: ?? ???? ???? /Revised: ?? ???? ???? /Accepted: ?? ???? ???? /Published online: ?? ???? ????

\begin{abstract}
Cell contact formation, which is the process by which cells are brought into close proximity is an important biotechnological process in cell and molecular biology. Such manipulation is achieved by various means, among which dielectrophoresis (DEP) is widely used due to its simplicity. Here, we show the advantages in the judicious choice of the DEP microelectrode configuration in terms of limiting undesirable effects of dielectric heating on the cells, which could lead to their inactivation or death, as well as the possibility for cell clustering, which is particularly advantageous over the linear cell chain arrangement typically achieved to date with DEP. This study comprises of experimental work as well as mathematical modeling using COMSOL. In particular, we establish the parameters in a capillary-based microfluidic system giving rise to these optimum cell-cell contact configurations, together with the possibility for facilitating other cell manipulations such as spinning and rotation, thus providing useful protocols for applica-
\end{abstract}

Electronic supplementary material The online version of this article (doi:???) contains supplementary material, which is available to authorized users.

Aminuddin Bin Ahmad Kayani aminuddin.kayani@mmu.edu.my

1 Institute of Microengineering and Nanoelectronics, Universiti Kebangsaan Malaysia, Bangi, Selangor 43600, Malaysia.

2 Faculty of Engineering and Technology, Multimedia University, Melaka, Melaka 75450, Malaysia.

3 Functional Materials and Microsystems Research Group, School of Engineering, RMIT University, Melbourne, Victoria 3001, Australia.

4 School of Engineering, RMIT University, Melbourne, Victoria 3001, Australia.

5 Biotechnology and Nanotechnology Research Centre, Malaysian Agricultural Research and Development Institute, 43400 Serdang, Selangor, Malaysia.

6 School of Chemistry, Physics, and Mechanical Engineering, Queensland University of Technology, Brisbane QLD 4000, Australia.

7 CSIRO-QUT Joint Sustainable Processes and Devices Laboratory, P. O. Box 218, Lindfield NSW 2070, Australia tion into microfluidic bioparticle manipulation systems for diagnostics, therapeutics or for furthering research in cellular bioelectricity and intercellular interactions.

Keywords Dielectrophoresis - Cell contact • Cell chain $\bullet$ Spinning $\bullet$ Rotation $\bullet$ Microfluidics

\section{Introduction}

Cell contact formation, which is the process of bringing cells of interest into close proximity such that physical touch between surfaces of the cells wall or membrane is formed, is an important protocol in cell and molecular biology studies and bioproduction processes, including studies of bioelectricity, cell signaling, extracellular matrix, immune system and electrofusion process (Gopalakrishnan et al. 2015; Liu et al. 2017; Neumann et al. 1989; Ogle et al. 2005; Pathak et al. 2012; Plonsey and Barr 2007; Robinson et al. 2014). Various techniques so far have been developed to drive cells into close contact, including the use of biochemical (e.g. avidin-biotin) (Li et al. 2014; Schmidt et al. 2013), chemical (e.g. polyethylene glycol) (Tesarik et al. 2000; Yang and Shen 2006), mechanical (e.g. centrifugation, hydrodynamics) (Schoeman et al. 2014; Tesarik et al. 2000) and electrical methods (Hu et al. 2013; Tresset and Takeuchi 2004). The latter approach employs the use of dielectrophoretic (DEP) forces (Çetin et al. 2014; Kayani et al. 2012b; Md Ali et al. 2016; Pethig 2010; Voldman 2006) by subjecting the cells to a non-uniform electric field through the application of high frequency alternating current (AC) voltages to manipulate the cells to close proximity (Van Pham et al. 2010; Tan and Takeuchi 2006).

The advancement of MEMS technology, in which DEP forces has been widely employed, has been adapted to biomedical studies and technology development. So-called BioMEMS, these microdevices include the application for biosensors and diagnostics (Longo et al. 2016; Shi et al. 2014; Tsai et al. 2010; 
Wasilewski et al. 2018; Xiong et al. 2015), drug delivery systems (Coffel and Nuxoll 2018; Nuxoll 2013), microsurgical (Abe et al. 2016; Soltanzadeh et al. 2017) as well as cell biology, proteomics and genomics studies (Ferrari 2007; Menon et al. 2013). In this work, the application of BioMEMS for cell biology studies is demonstrated, particularly in the formation of stable cell contact, towards applications for cellular bioelectricity and intercellular interactions.

Among the earliest works in DEP driven cell contact formation are those by Zimmerman who formed cell chains driven by $1 \mathrm{MHz}$ DEP (Zimmermann 1982) which later followed broadly by a number of research groups, most of which were driven at $\mathrm{MHz}$ order frequencies (Kemna et al. 2011; Robinson et al. 2014; Schoeman et al. 2014; Tresset and Takeuchi 2004). Latest, cell chains of B16-F1 cells was demonstrated at $2 \mathrm{MHz}$ DEP (Usaj et al. 2013). All of these indicate that works aiming on the stable cell contact formation have been inclined to the operation of $\mathrm{MHz}$ order high frequency AC signals, in the form of cell chains (Berg 1988; Dimitrov 1995; Gel et al. 2010; Hu et al. 2011; Rems et al. 2013; Wu et al. 2015; Zimmermann 1987). While all of these works aim to produce cell chain as precursor to conduct fusion, to the best of authors knowledge, none has been dedicated for cell bioelectricity studies, which is the primary focus of this work. Thus, the preliminary cell contact study is essential to provide various possible formation for aforementioned focus, which should not be limited to cell chain structure.

Cells are, however, susceptible to dielectric heating at $\mathrm{MHz}$ order frequencies, which arises as a consequence of the dissipation of heat from molecular friction when the dipole in the dielectric material, i.e. suspending media, continuously reorients to align with high frequency polarity change of the electric field (Gooch 2011; Mehdizadeh 2010; Nedelcu 2011; Piyasena et al. 2003; Shaparenko 2015). This could result in their exposure to heat shock and hence inactivation, or, worse, cell death. Thus, the control of heat effect is no less important than stable cells contact in DEP devices, which cause the demands for establishment of the parameter guideline.

In this work, we demonstrate that lower $\mathrm{kHz}$ order frequencies are advantageous as it is not only facilitating cells contact in the form of cell clusters but also subject the cells to less dielectric heating. In fact, cell clusters should be just as effective in assembling cells and offer far greater flexibility in terms of the number of cells that can be brought close together since clustering allows more than two cells to be assembled in close contact at a time in a circular configuration, which, given their linear arrangement, cannot be achieved when cell chains are produced; despite this, cell clustering has rarely been reported in the application of establishing optimum cell contact assemblies to our best knowledge, probably due to the lack of stability and the difficulty in achieving cell configurations from clusters (Hu et al. 2013; Pethig 2010; Pohl 1978; Qian et al. 2014; Şen et al. 2013).

In particular, we show the relationship between the microelectrode configuration, electric field distribution, electrical torque driven spinning-rotation and the impact of dielectric heating on temperature rise. In detail, we carefully study the dielectric heating effect upon extracellular and intracellular temperature, showing the frequency potential influence on the viability of the cells. Additionally, we show how the electric field distribution and frequency influences both cells contact configurations (cell chains and clusters), motions (cell spinning and cluster rotation), stability of the cells contact as well as the cellular activity.

Numerical modeling using COMSOL has been part of this study in the evaluation of electric field distribution across the platform, revealing that high electric field gradient spots at microelectrode tips effectively generated, which serves as focusing points for cells pulling or pushing under DEP effect.

Novelty of platform arises from the judicious DEP microelectrodes and flexibility of varying the applied electric fields to obtain optimum cell contact conditions. Negative (repelling) or positive (attracting) DEP forces (Kayani et al. 2012a; Morgan and Green 2015; Pohl 1978) can be applied and microfluidic structures such as filters or microvortices can be incorporated to isolate and perform desired protocol.

Judicious design of this novel microtip configurated electrode has equipped this platform with capability in demonstrating various bioparticles responses, namely chaining, clustering, repelling, attracting, spinning and rotation, within a non-sophisticated standard equipment setup, i.e. function generator with standard frequency range no more beyond several $\mathrm{MHz}$; which promotes the portability and low-cost establishment. In fact, the selection of deionized water as suspending media reveals evident responses of the bioparticles as well as ensure this system to be sustainable, chemicals-free, reproducible and environmentalfriendly as utmost important criteria in the development of diagnostic tools for resource limited area, such as point-of-care and war-torn situation.

We therefore believe that the establishment of these parameters serves as pragmatic guidelines that aid the design and optimization of DEP manipulation platforms for establishment of stable cell contact and their desired application. A further overview of DEP and dielectric heating effect is provided in the Online Resource 1 . 


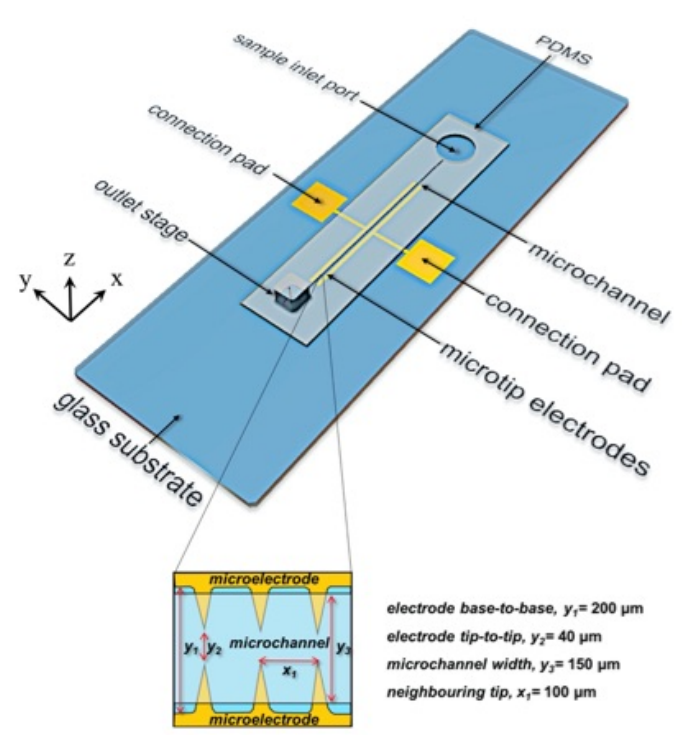

Fig.1 Schematic illustration of the DEP platform employed. Microelectrodes with microtip configurations, as shown in the inset, deposited on top of the glass slide are aligned with PDMS microchannel to exert a DEP force on the yeast cells. Current design is modifiable by scaling up or down according to targeted cells for further studies with different type of cells. Connection pads are provided for voltage supply. The sample inlet port facilitates introduction of the sample whereas the outlet stage is used for cleaning of the microchannel after the experiment.

\section{Materials and Methods}

\subsection{Device design and fabrication}

Fig. 1 shows a conceptual representation of the planar DEP cell manipulation platform. The platform consists of a glass microscope slide substrate (thickness = $1.2 \mathrm{~mm}$ ) with patterned DEP microtip electrodes, fabricated using standard photolithography and wet etching. The electrodes consist of a $50 \mathrm{~nm}$ chromium $(\mathrm{Cr})$ underlayer, which acts as an adhesion layer for the $150 \mathrm{~nm}$ conductive gold $(\mathrm{Au})$ overlayer serving as the electrodes. A $2 \mathrm{~mm}$ thick PDMS (DowCorning Corp, Sylgard 184) superstrate, fabricated using standard soft-lithography and comprising an inlet port, microchannel and outlet stage, is mounted on top of the glass substrate using an oxygen plasma bonding technique, details of which are provided in the Online Resource 1 . The sample inlet port is a $6 \mathrm{~mm}$ circular hole providing access to the horizontally connected $150 \mu \mathrm{m}$ $\times 50 \mu \mathrm{m}(\mathrm{w} \times \mathrm{h})$ microchannel, which extends to the outlet stage, which consisted of a base circle platform (diameter $=2.5 \mathrm{~mm}$ ) connected to a vertical outlet hole. The outlet stage is raised by $5 \mathrm{~mm}$ to provide a solid connection with a microfluidic tube (Tygon US Plastics, 1/32” ID).

\subsection{Sample preparation}

Yeast cells with concentration of $5 \times 10^{7}$ cells $/ \mathrm{mL}$ is prepared by suspension of yeast in deionized water (DIW). Yeast is reported to retain its viability in DIW and osmotic stress does not influence the viability (Adya et al. 2006), which further shown in this work. We use DIW instead of phosphate buffer saline (PBS) to provide a low conductivity suspending medium in order to observe the response of the yeast cells to the DEP force with higher sensitivity. In fact, by using DIW, electrically charged materials have been removed, hence providing accurate understanding of yeast cells sole responses to DEP field without disruption of other charged materials in suspension medium. While in PBS, eventhough it is much more-friendly to cells as the osmolarity and ion concentrations are close to human body, the dissolved salt ions do interact in the DEP field, thus influence the cells' responses.

The sample flow into the microchannel is driven by capillary forces, enhanced by the hydrophilization of the PDMS microchannel due to the oxygen plasma treatment (Yan et al. 2018). The microchannels were flushed with DIW prior to the experiments. The yeast suspension was sonicated in an ultrasonic bath for 30 min at $37{ }^{\circ} \mathrm{C}$ for optimal incubation as well as to avoid agglomeration or clustering. The response of the cells under DEP was then analyzed by introducing the suspension into the microfluidic channel followed by a buffer period of $30 \mathrm{~min}$ during which the suspension filled up the microchannel and yeast cells were exhibiting minimum localized motion or relative motional equilibrium. Observation of the yeast solution under bright field microscopy prior to the experiment confirms that the cells were in equilibrium and well dispersed before the application of the DEP force.

\subsection{Characterization of the cells' DEP response}

The setup employed to characterize the cellular response to DEP is described in detail in Online Resource 1. Specifically, the DEP platform is mounted on an optical microscope (Motic) and the observation image is projected onto a monitor. The yeast sample is introduced into the microfluidic channel by dripping $50 \mu \mathrm{L}$ of the solution into the sample inlet port, and allowing capillarity to fill it into the microchannel; the outlet is left open.

A function generator (Topward, 8120) is then used to apply a voltage to the electrodes, which subsequently be monitored with an oscilloscope (Tektronix, TDS1012B). The voltage and frequency amplitudes are set at $7 \mathrm{~V}_{\mathrm{rms}}\left(20 \mathrm{~V}_{\mathrm{pp}}\right)$, noting that it is widely reported that yeast cells remain viable at this voltage (Burgarella et al. 2015; Chu et al. 2014), while the frequency is carefully set to vary between $2 \mathrm{kHz}$ and 
$2 \mathrm{MHz}$, as AC electroosmosis effect may dominate at lower frequencies, i.e. less than $10 \mathrm{kHz}$, or in worse case, electrolysis which generate bubble may occur, consequently disrupt DEP (Kakaç 2010; Ramos 2011; Wu et al. 2005). These frequencies are chosen according to the estimation of the DEP crossover frequency (see Online Resource 1) of around $90 \mathrm{kHz}$, at which transition from positive DEP (pDEP) to negative DEP (nDEP) occurs. In this frequency range, we observe different cells contact configurations, namely, cell chaining(Rems et al. 2013; Wu et al. 2015) and clustering (Abdul Razak et al. 2013; Fernandez et al. 2016; Wu et al. 2005) with pDEP, as well as cell clustering with nDEP. Each particular frequency ranges at which pDEP cell chaining, pDEP cell clustering and nDEP cell clustering occurred are denoted as $f_{P C H}, f_{P C L}$ and $f_{N C L}$, respectively.

\subsection{Computations}

Numerical simulations of the real part of the ClausiusMossoti factor (Çetin and $\mathrm{Li} 2011) \operatorname{Re}\left[f_{C M}\right]$, the electric field $E$, the particle-independent DEP force $E^{2}$, electrical torque $T^{e}$ and the temperature rise $\Delta \vartheta$ influenced by the dielectric heating effect were performed, are described in the Online Resource 1. The ClausiusMossoti factor real component $\operatorname{Re}\left[f_{C M}\right]$ and the electrical torque action upon cells are computed using Octave 4.0 for a frequency range between $2 \mathrm{kHz}$ to $2 \mathrm{MHz}$; results indicate that yeast cells suspended in DIW experience nDEP force at low AC frequencies, while $\mathrm{pDEP}$ force is experienced at higher frequencies with transition from $\mathrm{nDEP}$ to $\mathrm{pDEP}$, and vice versa, takes place at $f_{x 0}=90 \mathrm{kHz}$, and torque peak is experienced at hundreds $\mathrm{kHz}$ frequency range. The electric field distributions $E$ and $E^{2}$ are simulated using COMSOL Multiphysics 5.1. The results are described in detail in Online Resource 1. The temperature rise $\Delta \vartheta$, upon extracellular and intracellular temperature due to dielectric heating effects can subsequently be calculated to predict its effect on cellular activity; the result indicates that temperature rises higher with frequency increase.

\subsection{Cell viability test}

Cell viability test is performed in this work by two method, i.e. trypan blue test and methylene blue test. For trypan blue test, yeast cells are stained by suspending them in trypan blue, and subsequently introduce to DEP platform for manipulation. While for methylene blue test, cells which exposed under each DEP manipulation $\left(20 \mathrm{~V}_{\mathrm{pp}}\right.$ with $2 \mathrm{MHz}, 200 \mathrm{kHz}$ or $20 \mathrm{kHz}$ for $5 \mathrm{~min}$ ), are extracted from device, then stained with methylene blue and evaluated. For both cases, cell viability is measured by cell count of transparent cell (live cell) vs dark cell (dead cell).

\section{Results and Discussion}

\section{1 pDEP cell chaining at high frequencies $\left(f>f_{P C L}\right)$}

Upon application of high frequencies ( $2 \mathrm{MHz}$ ), we observe the cells to first be attracted due to pDEP forces to the microtip electrode at which the field intensity $E^{2}$ is the largest, subsequently aligning to form chain-like structures, first at random positions throughout the microchannel between the microelectrode pairs (see Online Resource 2) before being attracted to the centerline between the microelectrode pairs where the electric field intensity is the largest (Fig. 2a). Whenever unconnected bridging chains exist, the yeast cells appear to move to fill in the gap to complete the bridging chain with the final form in linear or multilinear chain (Figs. 2b,c).

Whether single cell chains or multilinear cell chains form depends on the sample concentration, the former being favoured at low cell number concentrations comparable to the number of cells spatially required to bridge the gap between the edges of the opposing microtips and the latter at much higher cell numbers. We also note that it is possible that either configuration can exist due to the slight nonuniformity of the microelectrode structure arising from design limitations or by erosion due to repeated use resulting in a higher electric field generated at one microtip, and hence stronger attraction of the cells to this electrode compared to the others.

As shown in Fig. 2d, the chains are localized in a vicinity that spans a wide range of electric field intensities, from as high as $250 \mathrm{kV} / \mathrm{m}$ at the microtips edge to as low as $110 \mathrm{kV} / \mathrm{m}$ at the midpoint between the two opposing microtip electrodes. Once contact is established between the cells in these chain, no further motion, whether translational or rotational, is observed. This provides stable contact between cells, thus allowing them for subsequent research in establishing novel research applications such as intercellular communication, bioelectricity and electrofusion.

The mechanism by which the cell chain assemblies form is illustrated in Fig. 2e. There are generally two accepted interpretations by which cells assemble into chain-like structures, one of which involves nucleus dipole to dipole interactions, while the other considers the localized electric field disturbance caused by the dielectric particles (Jones 1995). Both approaches are considered in the description of our experimental result. More specifically, cells such as yeast consist of a 


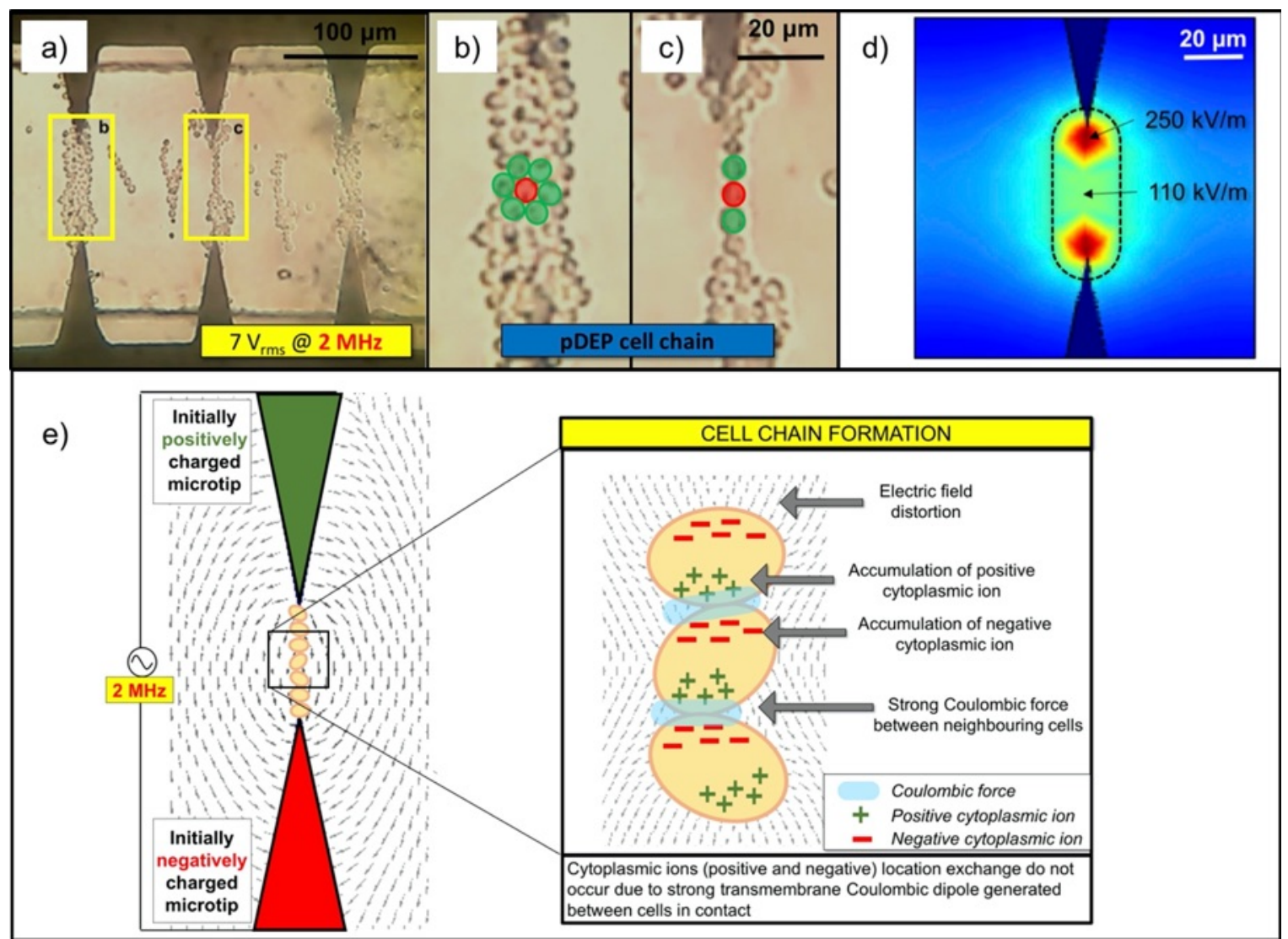

Fig. 2 (a) Formation of cell chain assemblies with high frequency pDEP ( $\left.2 \mathrm{MHz} ; 7 \mathrm{~V}_{\mathrm{rms}}\right)$ showing both (b) multidirectional and (c) unidirectional cells contact, as indicated by the cell labelled in red in contact with those labelled in green. (d) Magnified view of the electric field distribution $\mathrm{E}$ in the vicinity of the microtip electrodes, showing that the cells in these chain configurations are located in a region where the amplitude of the electric field ranges between 110 and $250 \mathrm{kV} / \mathrm{m}$. (e) Mechanism by which the cell chain assemblies form due to the transmembrane Coulombic attractive forces that arise between the field-induced cytoplasmic ion distributions of the neighbouring cells. (including simulated electric field flux)

dielectric membrane encapsulating its ionic cytoplasm. Upon application of the AC voltage to the microtip electrodes, ions in the cytoplasm are attracted to and accumulate along the side of the cell closer to the electrode with the opposing polarity, thus creating an effective cell dipole (Schaper J. 2007).

At frequencies of $2 \mathrm{MHz}$ or above, the initial charging induces a high ionic concentration at the poles of the cells, which consequently gives rise to a strong distortion of electric field in this polar region. The cytoplasmic ion cloud on each opposing side of the cell then attracts its counterpart in the neighbouring cell with opposite polarity, thus creating a transmembrane resting potential (Plonsey and Barr 2007) between two neighbouring cells due to the Coulombic force between them. The concentration of the ions that accumulate in the ion cloud continues to increase as dipoles in the cells drive ions in the vicinity of the active ion channels of the cell membrane to permeate into neighbouring cells once the transmembrane voltage reaches
0.5 to $1.0 \mathrm{~V}$ or the applied electric field is around $10^{2}-$ $10^{3} \mathrm{kV} / \mathrm{m}$ (Nickoloff 1995).

As the frequency of applied AC field extremely exceeds the capability of cytoplasmic ion cloud to cope with the frequency-dependent polarization change, the ion cloud which is inhomogeneous apparent stuck to initially polarized state, due to Maxwell-Wagner effect causing charge accumulation at interfacial layer (Iwamoto 2012), thus forming transmembrane Coulombic attraction between neighbouring cells, cause them to attach. As the neighbouring cells keep attracting each other, the cell chain length keep increasing until they bridge the interfacing electrode tips.

\section{2 pDEP cell clustering at intermediate frequen- cies $\left(f_{x o}<f<f_{P C H}\right)$}

By reducing the frequency to $200 \mathrm{kHz}$, which is still above the crossover $f_{x o}(90 \mathrm{kHz})$, we observe in Fig. 3a the cells to accumulate in the microtip region, again due to pDEP. In addition to exhibiting spinning 

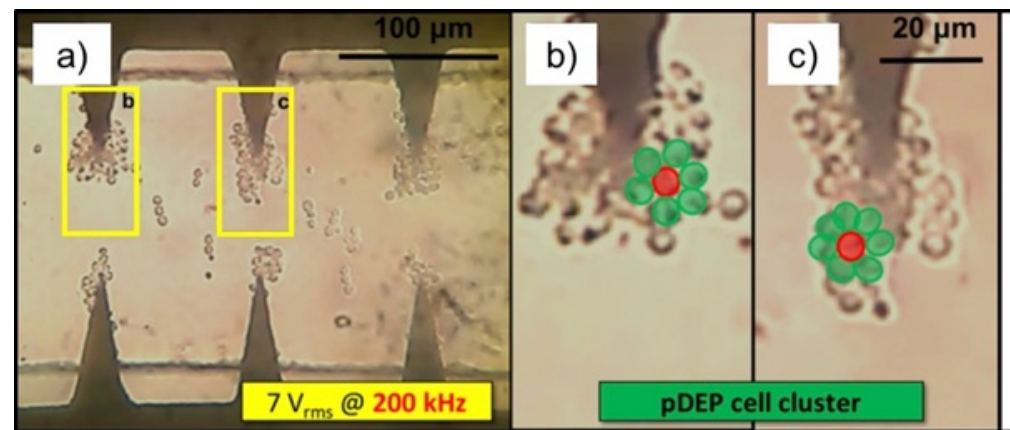

d)
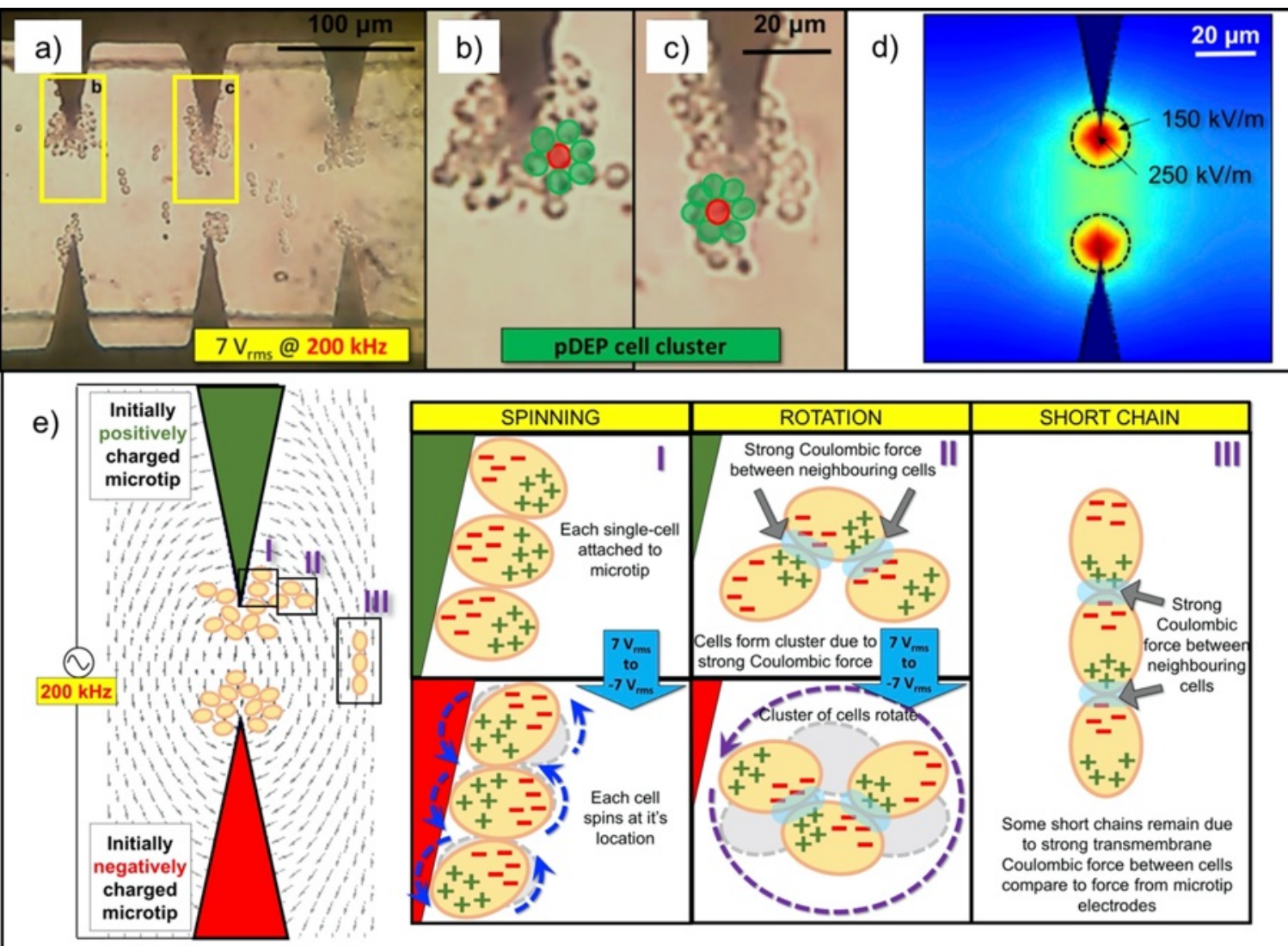

SHORT CHAIN
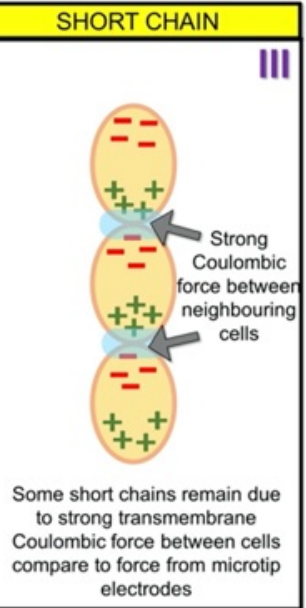

Fig. 3 (a) Cell clustering due to pDEP at intermediate frequencies $\left(200 \mathrm{kHz} ; 7 \mathrm{~V}_{\mathrm{rms}}\right)$, facilitating $(\mathrm{b}, \mathrm{c})$ multidirectional cells contact, as indicated by the cell labelled in red in contact with those labelled in green. (d) Magnified view of the electric field distribution E in the vicinity of the microtip electrodes, showing that the cells in these cluster configurations are located around the edge of the microtip electrodes where the amplitude of the electric field ranges between 150 and $250 \mathrm{kV} / \mathrm{m}$. (e) Mechanisms by which other effects such as spinning, rotation and short chain assemblies arise under this set of conditions. Spinning arises due to the Coulombic force acting on the cytoplasmic ion cloud in cells in contact with the microtip electrode. Rotation arises due to the same Coulombic force acting on the clouds of the cells at the edge of the cluster which are not cancelled by opposing ion clouds given there are no neighbouring cells unlike those within the cluster. Some remnant short cell chain assemblies are also observed if the transmembrane Coulombic force between the cells exceed that exerted by the electrode.

and rotational motion (Fig. 4a; see also Online Resource 3 and 4), the cells appear to form clusters chains observed previously in a much higher frequency. As in Fig. 3d, the cells congregate in a cluster which localized in a vicinity around the microtip electrode edge where the electric field intensity ranges between 250 to $150 \mathrm{kV} / \mathrm{m}$. These cell clusters facilitate multidirectional cells contact, (Figs. 3b,c), thus providing increased surface contact, compared to the unidirectional cells contact in single line chain configurations in previous. Nevertheless, the spinning (localized angular motion of a single cell with the center of rotation located at the center of the cell) and rotational (rotation of an entire cell cluster around an axis located within the cluster) motion potentially disrupts stable contact between the cells, thus providing less than optimal conditions for effective cell contact applications. around the microtip electrodes instead of the long range linear

As described in Fig. 3e, cell clusters in contact with the microtip electrodes edge undergo spinning due to the Coulombic force exerted on the cytoplasmic ion cloud of these cells by the electric field. Cells at the edge of the cluster, on the other hand, tend to experience rotational motion as a cluster since their ion clouds are not cancelled given the absence of any neighbouring cells and hence opposing ion clouds unlike those within the cluster. Such spinning and rotation is in sharp contrast to the cells subject to DEP at high frequencies $(2 \mathrm{MHz})$ in the previous which are strongly localized and do not exhibit spinning or rotation. Spinning and rotation demonstrated are however stable and consistent, which in our work, non-stop motion has been demonstrated up to 5 mins. In addition, 

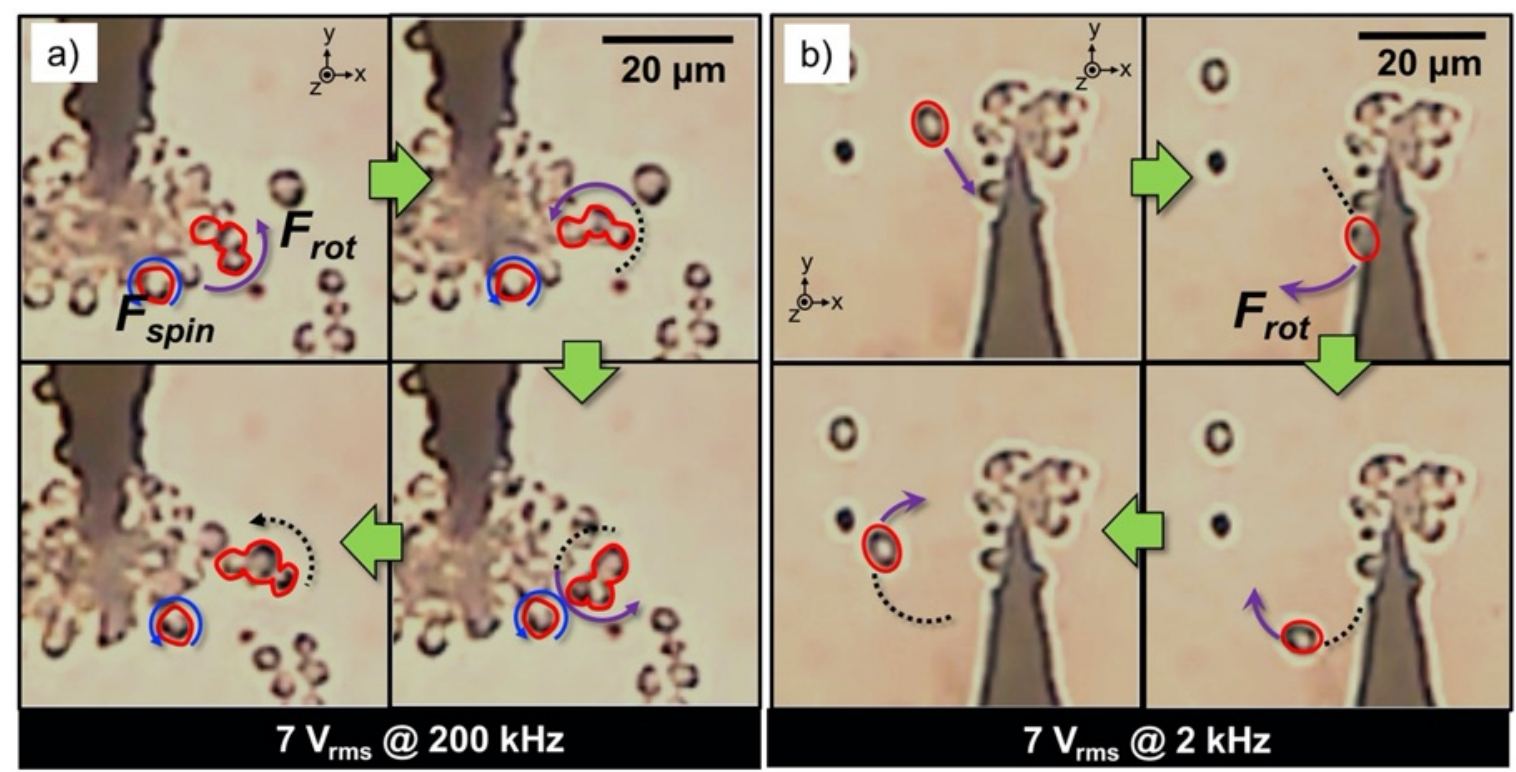

Fig. 4 (a) Localized spinning of a single cell (delineated in red and labelled $F_{\text {spin }}$ ) and rotation of a cluster of 3 cells (delineated in red and labelled $\left.F_{r o t}\right)$ at $7 \mathrm{~V}_{\text {rms }}$ and $200 \mathrm{kHz}$. The rotation center is at the center mean of the cluster and the radius of rotation is approximately $5 \mu \mathrm{m}$. (b) Bulk rotation of a single cell at $7 \mathrm{~V}_{\mathrm{rms}}$ and $2 \mathrm{kHz}$ in which the cell assumes a cyclic circular trajectory with a radius of approximately $10-15 \mu \mathrm{m}$, first towards the electrode before being repelled away repeatedly.

we also observe some remnant short chain cell assemblies particularly away from the electrode regions where the DEP force is insufficient to overcome the Coulombic force between the cells to break them. It seems that cell spinning and rotation are individual phenomena, i.e. some cells do not exhibit spinning and rotation, particularly which located close to the microelectrodes. We suspected that the cells' viability has been influenced by heating effect (discussed in later subsection), which induce different permittivity values hence changes the response to DEP fields.

Rotating cells may have been healthy while stationary cells are no longer viable. This is left as future research to focus on the cell viability, cell dormancy, latency or death.

To further understand cell spinning and rotation, we simulated the electrical torque that is generated by the AC electric field upon yeast cells, as detailed in Online Resource 1. The result indicates maximum torque magnitude occurs in the hundreds of $\mathrm{kHz}$ frequency range, which clearly proves why the spinning and rotation can be seen at $f=200 \mathrm{kHz}$. We quantitatively evaluate the spinning and rotation speed observed in this work, by selected four spinning cells in random position and single rotating cluster, in which the quantification method is described in Online Resource 1 . The cell spinning speed widely ranges between 15.7 to $45.1 \mathrm{rad} / \mathrm{sec}$, seems dependent to the position in the channel, while the cluster rotation speed is at $18.6 \mathrm{rad} / \mathrm{sec}$. It is observed that the spinning speed is higher at region closer to the microtip, however, the detail characterization of the spinning speed in regards with other parameters, such as distance from electrode, electrical frequency etc. are left as future work, as they are not the focus of current work, rather the aim is to obtain stable cell contact setup.

\section{3 nDEP cell clustering at low frequencies $\left(f<f_{x o}\right)$}

When the applied frequency is further decreased below the crossover frequency $f_{x o}$ to $20 \mathrm{kHz}$, we observe the cells to be repelled due to nDEP from regions of high field intensity in the vicinity of the microtip electrodes to regions of low field intensity between 10 and $50 \mathrm{kV} / \mathrm{m}$ near the microchannel side wall at the base regions of the microelectrodes where they accumulate (Figs. 5a,d,e). In a manner similar to the cell clusters at higher frequencies due to $\mathrm{pDEP}$, the clusters here also provide multidirectional cells contact (Figs. 5b,c) and hence the large contact areas to facilitate cell contact applications. Unlike their pDEP counterpart, however, the cells in these nDEP cluster configurations do not exhibit spinning and rotational motion, and hence are potentially more useful for establishing stable cells contact for effective applications (Online Resource

The absence of spinning and rotation can be attributed to the low density of the electric field flux in the base regions of the microelectrodes such that the $\mathrm{nDEP}$ force that drives the cells to this region is more dominant than either $F_{\text {spin }}$ or $F_{\text {rot }}$ (Fig. 5e-I). As a result, the cytoplasmic ion cloud concentration is also low, 


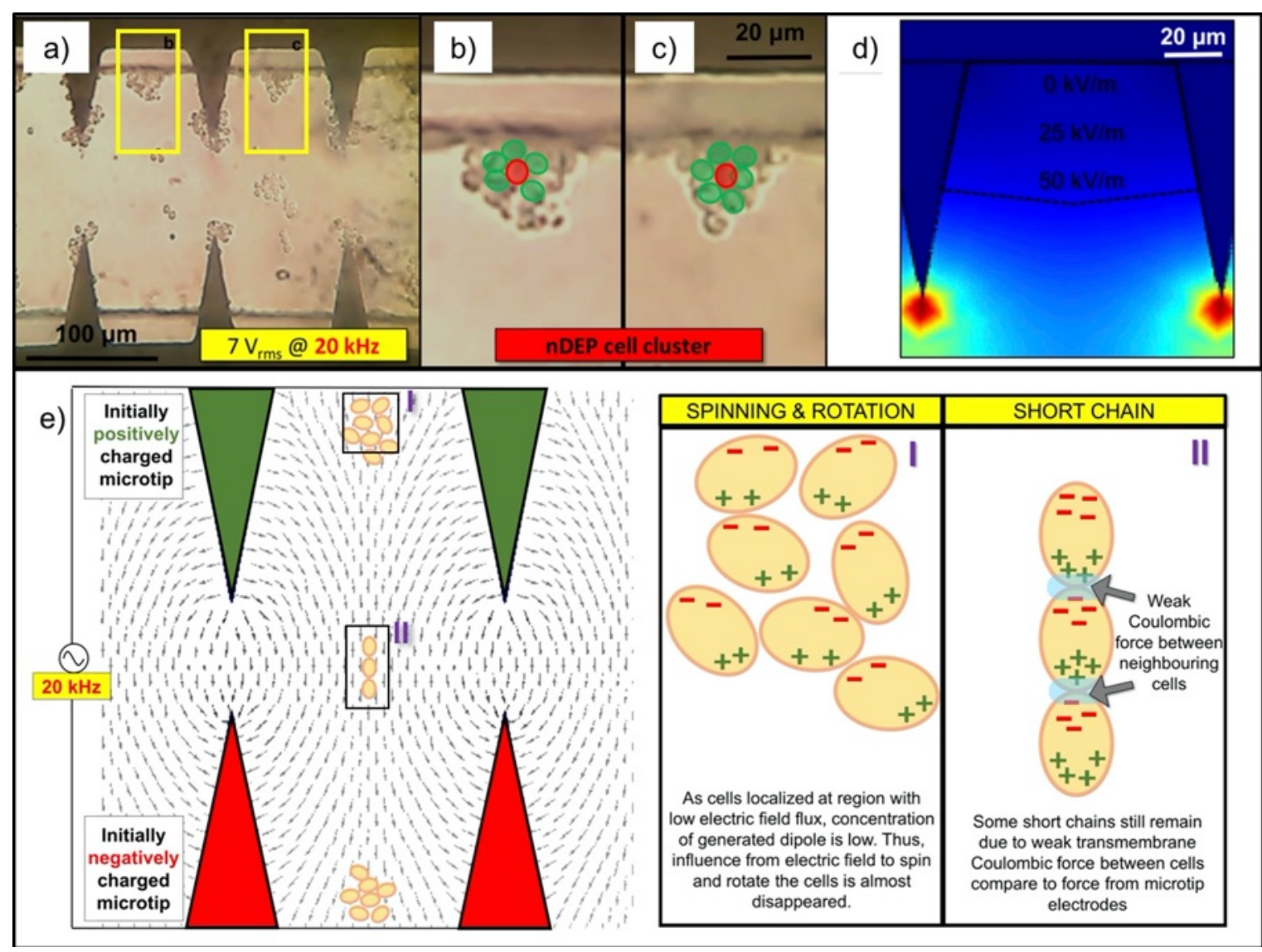

Fig. 5 (a) Cell clustering due to $\mathrm{nDEP}$ at low frequencies $\left(20 \mathrm{kHz} ; 7 \mathrm{~V}_{\mathrm{rms}}\right)$, facilitating (b,c) multidirectional cells contact, as indicated by the cell labelled in red in contact with those labelled in green. (d) Magnified view of the electric field distribution E in the vicinity of the microtip electrodes, showing that the cells in these cluster configurations are located in regions where the amplitude of the electric field ranges between $10 \mathrm{kV} / \mathrm{m}$ at the microchannel sidewall and $50 \mathrm{kV} / \mathrm{m}$. (e) Spinning and rotation are not evident at these low frequencies because the low electric field flux density at the electrode base regions (Region I) is insufficient to induce sufficiently strong cytoplasmic dipole forces. Short chain assemblies however still remain away from the microtip electrodes (Region II) because the cytoplasmic dipole induced in these regions and hence the transmembrane Coulombic force is still sufficiently strong.

giving rise to a weak effective dipole around the cell, which is also due to higher dipole generation of suspending medium at this nDEP frequency regime. Consequently, the influence of the electric field on the cell is weak and insufficient to drive their spinning and rotation.

Some short cell chain assemblies (less than 5-7 cells) remain along the centerline between the microtip electrode pairs away from the base electrode regions where the electric field intensity is still sufficiently large to provide an adequate Coulombic force between ion clouds of opposing polarity of neighbouring cells comparable to the DEP force which leads to their attraction (Fig. 3e-II). Further lowering the applied frequency $(2 \mathrm{kHz})$, however, leads to complete breaking of the short linear chain assemblies. At this frequency, dipoles are formed in the suspending medium, which together with the increase in electric field distortion within the suspending medium increased, give rise to a transmembrane dipole that overcomes the transmembrane Coulombic force holding the cells together in the chain.
In addition, the cells appear to resume their rotational motion, although the rotation, quite uniquely, does not occur along the cell axis but rather along field lines given that it is the alternating electric field that gives rise to a repetitive pull and push Coulombic force that acts repeatedly on these cells (Fig. 4b; Online Resource 6). This is most probably influenced by the AC electro-osmosis effect, which occurs when the applied AC frequency is at a range less than $f=1 / 2 \pi \tau$ (Castellanos et al. 2003; Ramos et al. 1998). wherein that frequency for this work is $2.3 \mathrm{kHz}$ while $\tau$ is the charge relaxation time.

Low frequency DEP does not aggregate cells into chaining as the cytoplasmic ion cloud retain their polarization change or circulation following the applied AC field, even their polarizability is less than the suspending medium. This is observed in our experiments as shown in Online Resource 5, where the slight spinning can be seen for cells that located at the microelectrode edges, where the electric field flux is high, indicate that polarization change of ion cloud still occur at this frequency. 


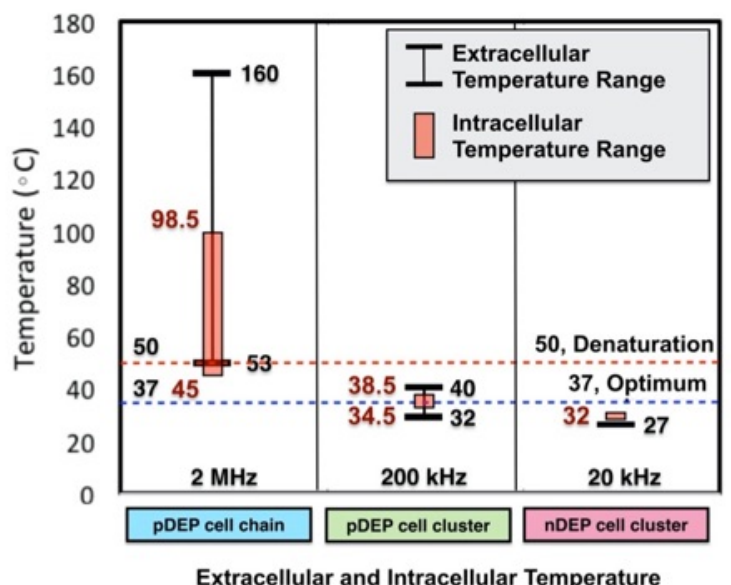

Fig. 6 Dielectric heating effect on the cells within various DEP cases examined. The temperature range shown as single black line is for the extracellular environment (suspending medium, DIW), while the red-colored bar is for the intracellular (cytoplasm) under respective extracellular environmental temperature, while cell intracellular initial temperature was $37^{\circ} \mathrm{C}$.

\subsection{Dielectric heating effect}

Dielectric heating concerns the heating of polarizable dielectric material by a high frequency $\mathrm{AC}$ electric field. The phenomenon is caused by dissipation of heat due to molecular friction when the dipole in the dielectric material continuously reorients under the high frequency field to align with polarity change (Gooch 2011). Given the susceptibility of cells to heating effects, particularly on their viability and activity, it is thus important to consider such effects during DEP. For the example of our model cell, i.e., yeast, it is ideal to operate at a temperature of $37{ }^{\circ} \mathrm{C}$ at which it is optimal for enzymatically catalysing various biochemical reactions (e.g., the production of ethanol from glucose or the enantioselective reduction of ketones). At $50{ }^{\circ} \mathrm{C}$, yeast is rendered inactive due to its plasma membrane phospholipid denaturation, unfolding and cell wall shrinkage (Adya et al. 2006; Stéphane et al. 2005).

Fig. 6 first reports the temperature increase at extracellular level, i.e. in the suspending medium due to such dielectric heating effects. At $2 \mathrm{MHz}$ in which the cells form linear chain assemblies under pDEP, the cells are subjected to intense dielectric heating primarily because they are driven to the high electric field intensity (110 to $250 \mathrm{kV} / \mathrm{m}$; Fig. $2 \mathrm{~d}$ ) regions at the microtips where the temperature of the surrounding medium rises to a range between 53 and $160{ }^{\circ} \mathrm{C}$, which is considerably above the denaturation temperature. It is thus likely that the cells in these chains would be rendered inactive and non-viable. At $200 \mathrm{kHz}$, despite the cell clusters accumulating around the microtip electrodes (Fig. 3a), the temperature rise is considerably less intense, ranging between 32 to $40{ }^{\circ} \mathrm{C}$ and hence we expect optimal activity of the cells using this configuration.

At $20 \mathrm{kHz}$ where the cell clusters are at the base of the electrodes, no temperature rise is detectable and the medium remains at room temperature. Dielectric heating increases with increasing $\mathrm{AC}$ frequency is consistent with that calculated from (Birle and Leu 2013; Mehdizadeh 2010; Piyasena et al. 2003)

$$
\Delta \vartheta=\frac{\omega \varepsilon^{\prime \prime} \varepsilon_{0} E^{2} V}{\alpha A_{c}}\left(1-e^{-\left(\frac{\alpha A c}{m c}\right) t}\right)
$$

in which $\varepsilon_{0}$ is the permittivity of free space, $V$ the volume of the suspending medium, $\alpha$ the heat transfer coefficient, $A_{c}$ is the effective surface area for heat convection, $m$ the mass, $c$ the heat capacity and $t$ the elapsed time.

We note that the temperature change $\Delta \vartheta$ is proportional to the angular frequency $\omega=2 \pi f$ of the applied $\mathrm{AC}$ field, wherein $f$ is the applied AC frequency, which is considerable given the three orders of magnitude change ( $2 \mathrm{kHz}$ to $2 \mathrm{MHz}$ ) examined in this work. The temperature change is also proportional to the imaginary part of complex permittivity $\varepsilon^{\prime \prime}$ of the suspending medium, i.e., DIW, which changes significantly from $\mathrm{MHz}$ to $\mathrm{GHz}$, while at lower frequencies, the variation of the complex permittivities is limited to below an order-of-magnitude (Andryieuski et al. 2015; Troiano et al. 2012). The temperature thus increases exponentially until it reaches an equilibrium.

However, we further perform a heat transfer simulation to calculate the temperature change experienced by the media surrounding the cell as well as the intracellular fluid within the cell as shown in Fig. 6. The cell interior temperature has been calculated in which the detail description is explained in Online Resource 1 (Lienhard IV and Lienhard V 2011). We notice that the extracellular media heated energy is significantly transferred across cell wall and membrane into intracellular element, in which at $2 \mathrm{MHz}$, the cytoplasm temperature could be increased up to the range between 45 to $98.5^{\circ} \mathrm{C}$. Exterior temperature beyond $63{ }^{\circ} \mathrm{C}$ could be the threshold for the cell denaturation as it causes the intracellular temperature exceeds $50{ }^{\circ} \mathrm{C}$. At $200 \mathrm{kHz}$ frequency, as the extracellular temperature varies close to intracellular initial temperature, the final intracellular temperature is keep within the optimum range. While at $20 \mathrm{kHz}$, as the extracellular temperature is lower than the intracellular, heat energy is transferred out from the cell causing the intracellular temperature slightly decreased to $32{ }^{\circ} \mathrm{C}$, however, turn closer to the optimum temperature.

Several measures can be taken to suppress the dielectric heating of high frequency DEP. One effective 
method is by changing the suspending medium surrounding the cells with higher heat capacity media while retaining low conductivity environment hence reducing dielectric heating. Application of a pulsed DEP which is broken into segmented time intervals is promising for heat reduction as it allow heat release between intervals. Usage of microelectrode arrays spaced further apart from the candidate cells will also reduce dielectric heating. However reduction in the resulting net DEP force will be lower. Hence, a better designed microelectrode structure may be necessary to counter these heating effects while applying a strong net displacement force onto the cells. Limiting the voltage magnitude to certain voltage, that should be simulated according to microelectrode design, also can reduce the dielectric heating effect.

As for cell manipulation in further studies, including intercellular communications and cell electrofusion, it is recommended to limit the frequencies used between direct current (DC) to tens of $\mathrm{MHz}$, as additional electric field imposed onto endogenous transmembrane voltage can affect voltage-sensitive proteins at the cell membrane (Voldman 2006). Besides, period length should be limited to a time-range below than milliseconds level for a case of DC application in pulsed form, to avoid cell lysis as well as ensuring membrane pore resealing (Kandušer and Miklavčič 2008; Neumann et al. 1989).

It should be noted that the temperature measurement results are simulated and not experimentally measured due to the closely spaced microelectrodes $(\sim 40 \mu \mathrm{m})$ and hence a high powered high resolution thermal imager would be required. Also, the temperature change in the microfluidic channel is highly timeand microfluidic-dependent. The capillary and forced convection within the microfluidic droplet induce flow of liquid from the bottom surface to flow upwards and the rate changes subject to hydrodynamic forces within the droplet itself. Recording such change using external equipment is almost impossible using such equipment. Therefore, the temperature measurements were conducted using simulations. The temperature is measured in the microfluidic media which is around the cells. Since yeast cells are impermeable to the media surrounding it, we cannot deduce that the temperature represents the same throughout the intracellular media but given that the diameter of the individual yeast cells are approximately $2-3 \mu \mathrm{m}$, and the bulk of the surrounding media represents more than $60-70 \%$ of the volume surrounding the cells, that the average temperature of the cells conform to its surrounding by a marginal error.

\subsection{Cell viability test}

We further perform the trypan blue and methylene blue cell viability assay to demonstrate the appropriateness of the developed method. Across the applied frequency, i.e. between $2 \mathrm{MHz}$ to $20 \mathrm{kHz}$, cells remain viable, proved by the high percentage of cells with transparent feature compared to dark cells as shown in Fig. 7 and Online Resource 1, where cell viability is 94 to $98 \%$ by trypan blue test while 92 to $96 \%$ by methylene blue. Trypan blue indicates cell viability in term of membrane integrity while methylene blue shows sub-cell enzymatic composition, where active enzyme in live cell reduced absorbed dye, thus live cells remain clear. Although it is predicted by dielectric heating effect that cells exposed to high frequency range, i.e. $2 \mathrm{MHz}$ or higher will caused the cells to die, it is however shown by viability assay that it is cells are not necessarily underwent denaturation when suffering high temperature environment. Due to low sample volume as well as short period exposure (max to 5 min), cells remain viable and can be used for further test.

\section{Conclusions}

The different cells contact configurations arising under different DEP frequencies with microtip electrodes for potential application in biomedical studies and processes have been discussed (summarized in Table 1).

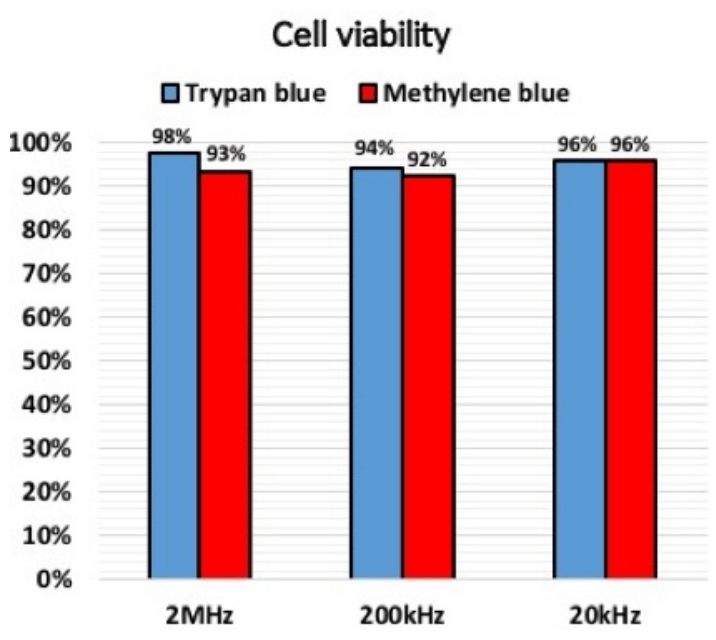

Fig. 7 Cell viability assay based on trypan blue and methylene blue assay methods. Yeast cells which exposed to $7 \mathrm{~V}_{\mathrm{rms}}$ at $2 \mathrm{MHz}$ (left), $200 \mathrm{kHz}$ (middle) and $20 \mathrm{kHz}$ (right) frequencies, respectively, demonstrate high viability percentages, both by trypan blue assay (with viability of 98, 94 and 96\%, respectively), and methylene blue assay (with viability of 98,92 and $96 \%$, respectively). 
Table 1 Comparison between the cells contact configurations that are observed for different DEP frequencies.

\begin{tabular}{lllll}
\hline Configuration & Frequency Range & Direction & Stability & Dielectric Heating \\
\hline pDEP cell chains & High $(f>1 \mathrm{MHz})$ & $\begin{array}{l}\text { Unidirectional \& } \\
\text { multidirectional }\end{array}$ & Stable & $\begin{array}{l}\text { Large temperature rise which } \\
\text { is potentially detrimental to } \\
\text { cellular activity }\end{array}$ \\
pDEP cell clusters & $\begin{array}{l}\text { Intermediate }(90 \mathrm{kHz}< \\
f<1 \mathrm{MHz})\end{array}$ & Multidirectional & $\begin{array}{l}\text { Unstable due to } \\
\text { cell spinning }\end{array}$ & $\begin{array}{l}\text { Temperature remains in a } \\
\text { range that preserves cellular } \\
\text { activity }\end{array}$ \\
nDEP cell clusters & Low $(f<90 \mathrm{kHz})$ & Multidirectional & Stable & Negligible temperature rise \\
\hline
\end{tabular}

Lower frequencies just above and below the crossover frequency lead to cell clusters in high and low electric field intensity regions, respectively, whereas high frequencies significantly beyond that which crossover occurs leads to the generation of single line and multilinear cell chain assemblies. The former, i.e., cell clustering provides opportunities for multidirectional cells contact, which, in cell electrofusion procedures for example, can be particularly advantageous for subsequent application of DC pulse voltages to trigger cell fusion either in-line, perpendicular or oblique to the direction of the applied AC potential for DEP, as is the case for the multilinear cell chains, whereas single line cell chains only facilitate unidirectional contact. This is promising for the enhancement in terms of adaptability of an electrofusion device.

Cell contact is time independent after the cells have made contact with each other due to the application of DEP fields. Once they have attached to each other, the cells are permanently attached until the DEP fields are disabled and a sufficiently strong hydrodynamic force need to be introduced to detach the cells and move them along the microfluidic channel. Hence the cell contact occurrence is in the case of our experiments, not time dependent but frequency and amplitude dependent, which providing stable form for further experiments or applications.

An inherent disadvantage of the pDEP cell clusters at intermediate frequencies, however, is the spinning and rotational motion that the cells are subjected to, which destabilizes the contact between the cells,however, this phenomena can be an adva ntage if being exploited to break any cell contact that has been established, such as to perform multiple stages of intercellular communication, let say cell A with cell B and later between cell $\mathrm{A}$ and cell $\mathrm{C}$ and so on. Linear chain assemblies which generated at $\mathrm{MHz}$ frequencies on the other hand suffer from large dielectric heating effects, which potentially leads to denaturation of the cells. As such, we have shown that it is typically advantageous to operate at low $\mathrm{AC}$ frequencies where the $\mathrm{nDEP}$ cell clusters are stable in the absence of spinning and rotation, and where the temperature rise due to dielectric heating effects are negligible such that the operation can be carried out at ambient temperatures optimum for cellular activity.
There are several recent works dedicated to the study on generation of controlled spinning of cells (Benhal et al. 2014; Soffe et al. 2015), however, the controlled cell spinning is not the aim of this work, rather this work focuses on the stability of cell contact formed by DEP, which could be utilized for biomedical and clinical tools benefited from cell contact. The spinning and rotation is reported here to demonstrate how the selection of frequency range can influence the stability of cell contact. As the focus differ, those works employ sophisticated setup, either in the electrode structure (multi layers, vertical standing electrodes etc.), the electrical signal (several signal sources with phase-shift mode to induce electro-rotation) or suspending media modification (different type of suspending media or mixture of them) to achieve their aim.

One should note also that there are also a number of previous work demonstrating the capability of forming cell cluster based on DEP force (Pethig et al. 1992; Soffe et al. 2015; Zhu et al. 2010), however in this work, we refine those work by demonstrating that the DEP occurs at low frequencies is advantageous than high frequency in term of limiting the thermal effect by dielectric heating, as well as instability of the cell contact affected by spinning and rotation.

Yeast cells is a known model organism for variety of applications leading to cancer and non-cancer cells, including for studying cellular processes such as cell cycle, cell division, metabolism, DNA replication and recombination (Alberts et al. 2008; Nitiss and Heitman 2007). Using yeast cells has been prominent widely in DEP and other bioparticle manipulation methodologies as a proof of concept (Botstein and Fink 2011; Smith and Snyder 2001; Verduyckt et al. 2016). If we dealt with a variety of cells in this stage of research, the number of variables would be increased hence making it difficult to demonstrate viability of using this microfluidic platform combined with the microtip electrodes for this purpose. Using synthetic particles has been demonstrated before widely (Ding et al. 2015; Doh-Hyoung et al. 2011; García et al. 2010; Nishimura et al. 2010; Otsuki and Sagawa 2010). 
Table 2 Summary of our achievements compared to those of prior works.

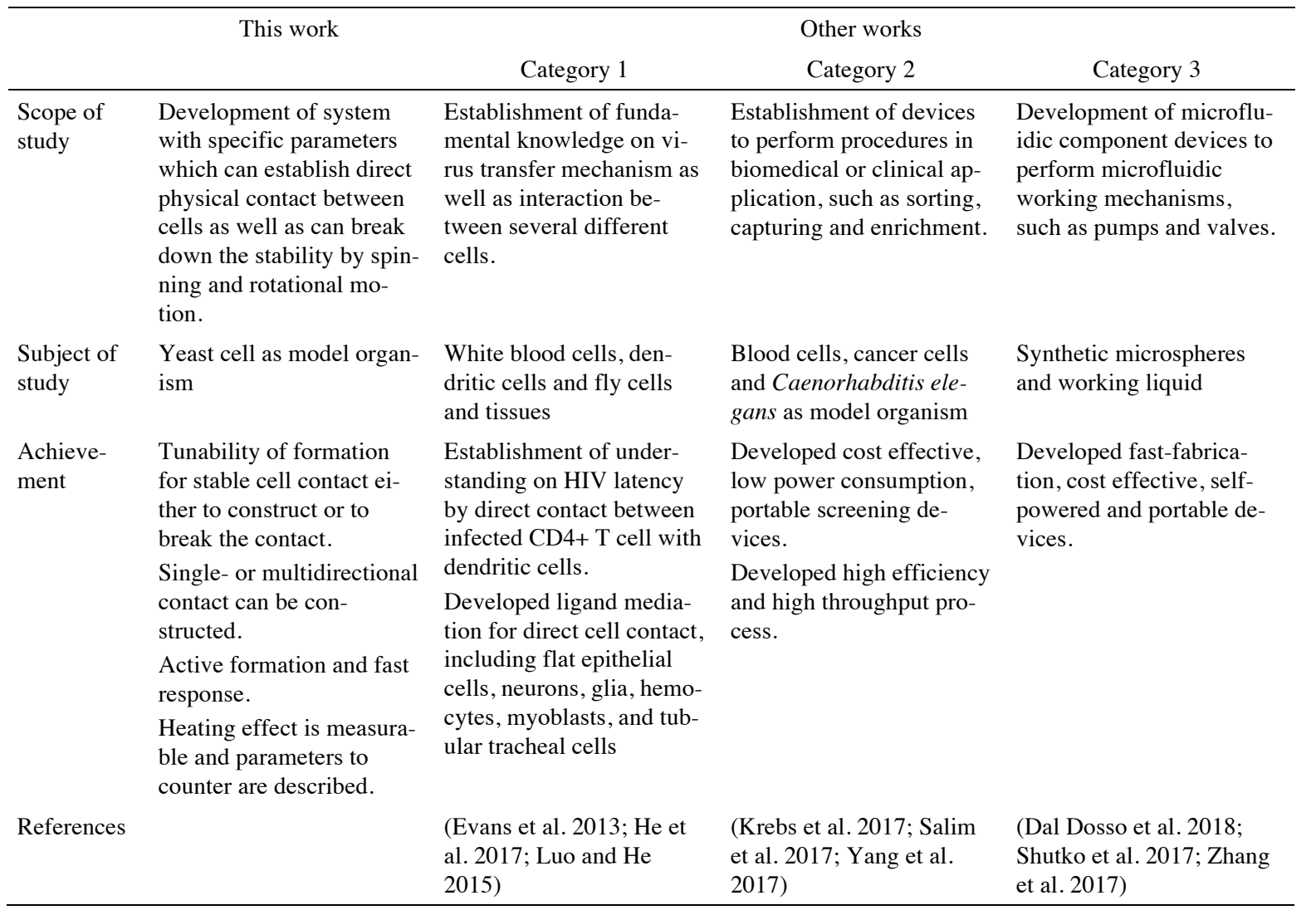

Another difficulty of using cells is different live cells have different preparatory processes and living conditions which need to be suited to the experiments. Further, this microfluidic platform is demonstrating a fundamental viability and not at the device development stage. We have presented microfluidic BioMEMS platform which induces stable cell contact based on DEP using yeast cells. This is an important milestone in developing microfluidic platforms which can establish stable cell contact assemblies for subsequent bioelectricity studies as well cell fusion. The existing templates of microfluidic platforms have not achieved this task as they have been mainly focus towards studies on fundamental knowledge of biological behavior, or development of microfluidic components, or establishing biomedical procedures in microfluidic BioMEMS. We highlight the summary of our achievements compared to those of prior works in Table 2.

Acknowledgements We thank the Ministry of Higher Education of Malaysia (MOHE) for support under Fundamental Research Grant Scheme (FRGS) FRGS/2/2013/TK03/UKM/ 01/1 and FRGS/1/2015/TK04/MMU/02/9 and the Ministry of Education of Malaysia (MOE) for support under the Higher Institution Centre of Excellence (HiCOE) Grant, AKU-95. Dr Adam Chrimes acknowledges the support of the Victorian Government through the 2015 Victorian Postdoctoral Research Fellowship program. Professor Leslie Yeo is grateful to the Australian Research Council for a Future Fellowship (FT130100672).

\section{References}

M. A. Abdul Razak, K. F. Hoettges, H. O. Fatoyinbo, F. H. Labeed, M. P. Hughes, Biomicrofluidics 7, 064110 (2013).

Y. Abe, K. Nagamine, M. Nakabayashi, H. Kai, H. Kaji, T. Yamauchi, K. Yamasaki, M. Nishizawa, Biomed. Microdevices 18, 55 (2016).

A. K. Adya, E. Canetta, G. M. Walker, FEMS Yeast Res. 6, 120 (2006).

B. Alberts, A. Johnson, J. Lewis, M. Raff, K. Roberts, P. Walter, J. Wilson, T. Hunt, Molecular Biology of the Cell, 5th edition (Garland Science, New York, 2008).

A. Andryieuski, S. M. Kuznetsova, S. V Zhukovsky, Y. S. Kivshar, A. V Lavrinenko, Sci. Rep. 5, 13535 (2015).

P. Benhal, J. G. Chase, P. Gaynor, B. Oback, W. Wang, Lab Chip 14, 2717 (2014).

H. Berg, in Mod. Bioelectr., ed. by A. A. Marino (CRC Press, New York, 1988), p. 269.

M. Birle, C. Leu, in 18th Int. Symp. High Volt. Eng. (Seoul, 2013), p. 1025.

D. Botstein, G. R. Fink, Genetics 189, 695 (2011).

S. Burgarella, M. Di Bari, B. Sarah, B. M. Di, Electrophoresis 36, 1466 (2015).

A. Castellanos, A. Ramos, A. González, N. G. Green, H. Morgan, J. Phys. D. Appl. Phys. 36, 2584 (2003).

B. Çetin, D. Li, Electrophoresis 32, 2410 (2011).

B. Çetin, M. B. Özer, M. E. Solmaz, Biochem. Eng. J. 92, 63 (2014).

H. K. Chu, Z. Huan, J. K. Mills, J. Yang, D. Sun, in IEEE Int. Conf. Intell. Robot. Syst. (Chicago, 2014), p. 2003.

J. Coffel, E. Nuxoll, Int. J. Pharm. 544, 335 (2018). 
F. Dal Dosso, T. Kokalj, J. Belotserkovsky, D. Spasic, J. Lammertyn, Biomed. Microdevices 20, 44 (2018).

D. S. Dimitrov, in Handb. Biol. Phys., ed. by R. Lipowsky and E. Sackmann (Elsevier, Amsterdam, 1995), p. 851.

H. Ding, J. Shao, Y. Ding, W. Liu, X. Li, H. Tian, Y. Zhou, Appl. Surf. Sci. 330, 178 (2015).

L. Doh-Hyoung, Y. Chengjie, P. Elisabeth, F. Bakhtier, N. H. M., Electrophoresis 32, 2298 (2011).

V. A. Evans, N. Kumar, A. Filali, F. A. Procopio, O. Yegorov, J. P. Goulet, S. Saleh, E. K. Haddad, C. da Fonseca Pereira, P. C. Ellenberg, R. P. Sekaly, P. U. Cameron, S. R. Lewin, PLoS Pathog. 9, 1 (2013).

R. E. Fernandez, B. J. Sanghavi, V. Farmehini, J. L. Chávez, J. Hagen, N. Kelley-Loughnane, C.-F. Chou, N. S. Swami, Electrochem. Commun. 72, 144 (2016).

M. Ferrari, BioMEMS and Biomedical Nanotechnology. (Springer US, Boston, 2007).

N. García, E. Benito, P. Tiemblo, M. M. B. Hasan, A. Synytska, M. Stamm, Soft Matter 6, 4768 (2010).

M. Gel, Y. Kimura, O. Kurosawa, H. Oana, H. Kotera, M. Washizu, Biomicrofluidics 4, 022808 (2010).

J. W. Gooch, in Encycl. Dict. Polym., ed. by J. W. Gooch (Springer-Verlag New York, New York, 2011), p. 213.

N. Gopalakrishnan, R. Hannam, G. P. Casoni, D. Barriet, J. M. Ribe, M. Haug, O. Halaas, Lab Chip 15, 1481 (2015).

L. He, J. Huang, N. Perrimon, Proc. Natl. Acad. Sci. 114, 5467 (2017).

N. Hu, J. Yang, S. W. Joo, A. N. Banerjee, S. Qian, Sensors Actuators, B Chem. 178, 63 (2013).

N. Hu, J. Yang, S. Qian, S. W. Joo, X. Zheng, Biomicrofluidics 5, 034121 (2011).

M. Iwamoto, in Encycl. Nanotechnol., ed. by B. Bhushan (Springer Netherlands, Dordrecht, 2012), p. 1276.

T. B. Jones, Electromechanics of Particles (Cambridge University Press, Cambridge; New York, 1995).

S. Kakaç, Microfluidics Based Microsystems Fundamentals and Applications (Springer Netherlands, Dordrecht, 2010).

M. Kandušer, D. Miklavčič, in Electrotechnol. Extr. from Food Plants Biomater., ed. by E. Vorobiev and N. Lebovka (Springer-Verlag New York, New York, 2008), p. 1.

A. A. Kayani, K. Khoshmanesh, T. G. Nguyen, G. Kostovski, A. F. Chrimes, M. Nasabi, D. A. Heller, A. Mitchell, K. Kalantar-zadeh, Electrophoresis 33, 2075 (2012a).

A. A. Kayani, K. Khoshmanesh, S. A. Ward, A. Mitchell, K. Kalantar-zadeh, Biomicrofluidics 6, 31501 (2012b).

E. W. M. Kemna, F. Wolbers, I. Vermes, A. van den Berg, Electrophoresis 32, 3138 (2011).

J. C. Krebs, Y. Alapan, B. A. Dennstedt, G. D. Wera, U. A. Gurkan, Biomed. Microdevices 19, 20 (2017).

J. Li, X. Yu, T. E. Wagner, Y. Wei, Oncol. Lett. 8, 198 (2014).

J. H. Lienhard IV, J. H. Lienhard V, A Heat Transfer Textbook (Dover Publications, New York, 2011).

A. P. Liu, O. Chaudhuri, S. H. Parekh, Integr. Biol. 9, 383 (2017).

A. Longo, A. Baraket, M. Vatteroni, N. Zine, J. Baussells, RogerFuoco, F. Di Francesco, G. S. Karanasiou, D. I. Fotiadis, A. Menciassi, A. Errachid, Procedia Eng. 168, 97 (2016).

X. Luo, J. J. He, J. Neurovirol. 21, 66 (2015).

M. A. Md Ali, K. (Ken) Ostrikov, F. A. Khalid, B. Y. Majlis, A. A. Kayani, RSC Adv. 6, 113066 (2016).

M. Mehdizadeh, Microwave/RF Applicators and Probes for Material Heating, Sensing, and Plasma Generation (Elsevier, Amsterdam; Boston, 2010).

K. Menon, R. A. Joy, N. Sood, R. K. Mittal, Bionanoscience 3, 356 (2013).

H. Morgan, N. Green, in Encycl. Microfluid. Nanofluidics, ed. by D. Li (Springer US, New York, 2015), p. 563.
O. T. Nedelcu, Rom. J. Inf. Sci. Technol. 14, 309 (2011).

E. Neumann, A. E. Sowers, C. A. Jordan, Electroporation and Electrofusion in Cell Biology (Plenum Press, New York, 1989).

J. A. Nickoloff, Animal Cell Electroporation and Electrofusion Protocols (Humana Press, Totowa, NJ, 1995).

S. Nishimura, H. Matsumura, K. Kosuge, T. Yamaguchi, Langmuir 26, 10357 (2010).

J. L. Nitiss, J. Heitman, Yeast as a Tool in Cancer Research (Springer Netherlands, Dordrecht, 2007).

E. Nuxoll, Adv. Drug Deliv. Rev. 65, 1611 (2013).

B. M. Ogle, M. Cascalho, J. L. Platt, Nat Rev Mol Cell Biol 6, 567 (2005).

A. Otsuki, T. Sagawa, in Chemeca 2010 Eng. Edge (South Australia, 2010), p. 2568.

D. T. Pathak, X. Wei, A. Bucuvalas, D. H. Haft, D. L. Gerloff, D. Wall, PLoS Genet. 8, 1 (2012).

R. Pethig, Biomicrofluidics 4, 022811 (2010).

R. Pethig, Y. Huang, X. Wang, J. P. H. Burt, J. Phys. D. Appl. Phys. 25, 881 (1992).

N. Van Pham, J. Villemejane, F. Hamdi, G. Mottet, C. Dalmay, M. Woytasik, E. Martincic, E. Dufour-Gergam, O. Français, L. M. Mir, B. Le Pioufle, Procedia Eng. 5, 49 (2010).

P. Piyasena, C. Dussault, T. Koutchma, H. S. Ramaswamy, G. B. Awuah, Crit. Rev. Food Sci. Nutr. 43, 587 (2003).

R. Plonsey, R. C. Barr, Bioelectricity (Springer US, Boston, 2007).

H. A. Pohl, Dielectrophoresis : The Behavior of Neutral Matter in Nonuniform Electric Fields (Cambridge University Press, Cambridge; New York, 1978).

C. Qian, H. Huang, L. Chen, X. Li, Z. Ge, T. Chen, Z. Yang, L. Sun, Int. J. Mol. Sci. 15, 18281 (2014).

A. Ramos, Electrokinetics and Electrohydrodynamics in Microsystems (Springer-Verlag Wien, New York, 2011).

A. Ramos, H. Morgan, N. G. Green, A. Castellanos, J. Phys. D. Appl. Phys. 31, 2338 (1998).

L. Rems, M. Ušaj, M. Kandušer, M. Reberšek, D. Miklavčič, G. Pucihar, Sci. Rep. 3, 3382 (2013).

T. Robinson, P. E. Verboket, K. Eyer, P. S. Dittrich, Lab Chip 14, 2852 (2014)

B. Salim, M. V Athira, A. Kandaswamy, M. Vijayakumar, T. Saravanan, T. Sairam, Biomed. Microdevices 19, 89 (2017).

Schaper J., Development of a Technology for Arranged Electrofusion of Mammalian Cells: Applicability in Breast Cancer Immunotherapy, Bielefeld University, 2007.

F. I. Schmidt, P. Kuhn, T. Robinson, J. Mercer, P. S. Dittrich, Biophys. J. 105, 420 (2013).

R. M. Schoeman, E. W. M. Kemna, F. Wolbers, A. van den Berg, Electrophoresis 35, 385 (2014).

M. Şen, K. Ino, J. Ramón-Azcón, H. Shiku, T. Matsue, Lab Chip 13, 3650 (2013).

B. Shaparenko, The Thermal Dielectrophoretic Force On A Dielectric Particle In Electric And Temperature, University of Pennsylvania, 2015.

Q. Shi, J. Wang, D. Chen, J. Chen, J. Li, K. Bao, Biomed. Microdevices 16, 859 (2014).

A. V Shutko, V. S. Gorbunov, K. G. Guria, K. I. Agladze, Biomed. Microdevices 19, 72 (2017).

M. G. Smith, M. Snyder, in Curr. Protoc. Hum. Genet. (Wiley, New York, 2001), p. 15.6.1.

R. Soffe, S.-Y. Tang, S. Baratchi, S. Nahavandi, M. Nasabi, J. M. Cooper, A. Mitchell, K. Khoshmanesh, Anal. Chem. 87, 2389 (2015).

R. Soltanzadeh, E. Afsharipour, C. Shafai, N. Anssari, B. Mansouri, Z. Moussavi, Biomed. Microdevices 20, 1 (2017).

G. Stéphane, F. Eric, G. Patrick, Biotechnol. Bioeng. 92, 403 (2005).

W.-H. Tan, S. Takeuchi, Lab Chip 6, 757 (2006). 
J. Tesarik, Z. P. Nagy, C. Mendoza, E. Greco, Hum. Reprod. 15, 1149 (2000).

G. Tresset, S. Takeuchi, Biomed. Microdevices 6, 213 (2004).

A. Troiano, E. Pasero, L. Mesin, in New Adv. Veh. Technol. Automot. Eng., ed. by J. P. Carmo and J. E. Ribeiro (IntechOpen, Rijeka, 2012), p. 231.

H.-H. Tsai, C.-F. Lin, Y.-Z. Juang, I.-L. Wang, Y.-C. Lin, R.L. Wang, H.-Y. Lin, Sensors Actuators B Chem. 144, 407 (2010).

M. Usaj, K. Flisar, D. Miklavcic, M. Kanduser, Bioelectrochemistry 89, 34 (2013).

M. Verduyckt, H. Vignaud, T. Bynens, J. Van den Brande, V. Franssens, C. Cullin, J. Winderickx, in Syst. Biol. Alzheimer's Dis., ed. by J. I. Castrillo and S. G. Oliver (Springer, New York, 2016), p. 197.

J. Voldman, Annu. Rev. Biomed. Eng. 8, 425 (2006).

T. Wasilewski, J. Gębicki, W. Kamysz, Sensors Actuators, B Chem. 257, 511 (2018).

J. Wu, Y. Ben, D. Battigelli, H. C. Chang, Ind. Eng. Chem. Res. 44, 2815 (2005).

W. Wu, Y. Qu, N. Hu, Y. Zeng, J. Yang, H. Xu, Z. Q. Yin, PLoS One 10, 1 (2015).

L. Xiong, Y. Yan, M. Jiahao, Z. Yanhang, W. Qian, Z. Zhaohua, R. Tianling, J. Semicond. 36, 64009 (2015).

S. Yan, Y. Zhu, S.-Y. Tang, Y. Li, Q. Zhao, D. Yuan, G. Yun, J. Zhang, S. Zhang, W. Li, Electrophoresis 39, 957 (2018).

J. Yang, M. H. Shen, in Nucl. Reprogramming Methods Protoc., ed. by S. Pells (Humana Press, Totowa, 2006), p. 59.

L. Yang, T. Hong, Y. Zhang, J. G. S. Arriola, B. L. Nelms, R. Mu, D. Li, Biomed. Microdevices 19, 38 (2017).

X. Zhang, Z. Zhu, Z. Ni, N. Xiang, H. Yi, Biomed. Microdevices 19, 21 (2017).

K. Zhu, A. S. Kaprelyants, E. G. Salina, G. H. Markx, Biomicrofluidics 4, 022809 (2010).

U. Zimmermann, Biochim. Biophys. Acta - Rev. Biomembr. 694, 227 (1982).

U. Zimmermann, in Methods Hybrid. Form., ed. by A. H. Bartal and Y. Hirshaut (Humana Press, Totowa, NJ, 1987), p. 97. 